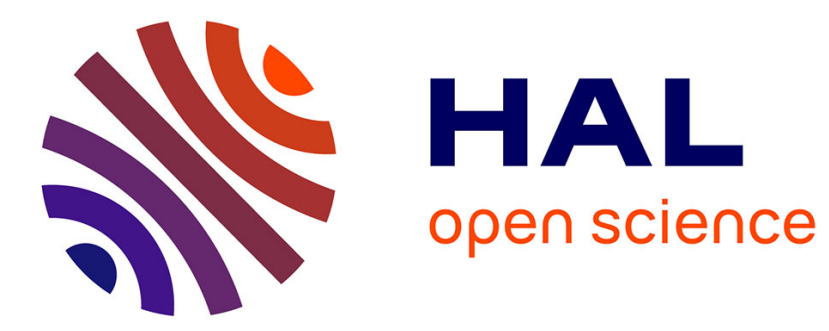

\title{
The Leverage Ratio as a Bank Discipline Device
}

Clovis Rugemintwari

\section{To cite this version:}

Clovis Rugemintwari. The Leverage Ratio as a Bank Discipline Device. Revue Economique, 2011, 62 (3), pp.479-490. 10.3917/reco.623.0479 . hal-00785487

\section{HAL Id: hal-00785487 \\ https://hal-unilim.archives-ouvertes.fr/hal-00785487}

Submitted on 12 Nov 2014

HAL is a multi-disciplinary open access archive for the deposit and dissemination of scientific research documents, whether they are published or not. The documents may come from teaching and research institutions in France or abroad, or from public or private research centers.
L'archive ouverte pluridisciplinaire HAL, est destinée au dépôt et à la diffusion de documents scientifiques de niveau recherche, publiés ou non, émanant des établissements d'enseignement et de recherche français ou étrangers, des laboratoires publics ou privés. 
This paper investigates bank portfolio composition under Basel II where the amount of required capital is determined by bank's own risk assessment. We particularly show that in presence of asymmetric information between the bank and the supervisor, it has incentives to understate its risk taking which could be curbed by the addition of the simple leverage ratio as suggested in Basel III.

\section{LE RATIO DE LEVIER COMME FACTEUR DISCIPLINANT DES BANQUES}

Cet article étudie le choix de portefeuille sous le dispositif de Bâle II dans lequel la banque détermine le montant du capital requis en fonction de sa propre mesure du risque. Nous montrons en particulier qu'en présence d'asymétrie d'information entre la banque et le superviseur, cette dernière a des incitations à sous-estimer sa prise de risque. Ces incitations sont tempérées par l'adjonction du simple levier comme envisagé dans le dispositif Bâle III.

JEL Classification: G21, G28, G32

\section{INTRODUCTION}

The previous literature (Furfine [2001], Repullo and Suarez [2004], Rime [2005] for instance) that analyzed the potential impact of Basel II has mainly converged in predicting a potential bank specialization. Banks adopting Basel II should concentrate on low risk assets and offer competitive borrowing conditions to this type of borrowers whereas those that stick to Basel I would specialize in high risk assets. This conjecture has been derived merely focusing on Pillar 1. Our first contribution is to show that this result no longer holds once we consider the asymmetric information that could exist between the bank and the supervisor during the supervisory review process (Pillar 2) and we also show that, in this imperfect supervision framework, banks have incentives to understate their risk taking. This leads us to our second contribution that consists in studying what could be, in this context, the benefits of coupling Basel II with a simple leverage ratio. This investigation is justified by the recent propositions known as Basel III which include the simple leverage ratio as a supplement to Basel II (Caruana [2010]).

\footnotetext{
${ }^{*}$ Université de Limoges, LAPE, 5 rue Félix Eboué BP 3127, 87031 Limoges, France. E-mail address: clovis.rugemintwari@unilim.fr

A longer version of this paper has been presented at the 2010 AFFI Spring meeting in Saint-Malo and the $59^{\text {th }}$ AFSE annual Congress in Paris. I thank all the seminar participants, particularly Franck Moraux for his discussion. Without implicating them, I would like to thank also my supervisor Prof. Alain Sauviat and Isabelle Distinguin for their helpful insights. All errors are my own.
} 


\section{MODEL SET UP}

The bank is assumed to have a representative balance sheet comprised of, on the asset side, commercial loans $\mathrm{L}$ with inherent and discernable differences in their credit risk, and idle reserves $\mathrm{R}$. On the liability side it has deposits $\mathrm{D}$ and capital $\mathrm{K}$. Thus, the balance sheet condition requires that $\mathrm{R}+\mathrm{L}=\mathrm{D}+\mathrm{K}$. As it is usually assumed, we consider that the loan market comprises both low and high risk borrowers. Therefore, we have two types of commercial loans: $\mathrm{L}_{\mathrm{L}}$ for low risk loans and $\mathrm{L}_{\mathrm{H}}$ for high risk loans $\left(\mathrm{L}=\mathrm{L}_{\mathrm{L}}+\mathrm{L}_{\mathrm{H}}\right)$.

The main objective of Basel II is to link appropriately the capital requirement to the risk taken. Hence, even for the same category of corporate loans, low risk loans receive a low risk weight $w_{L}$ while high risk loans receive a high risk weight $w_{H}$. Thus, the regulatory capital ratio is computed as $k_{2}=\frac{K}{w_{L} L_{L}+w_{H} L_{H}} \geq k$ where $k$ and $k_{2}$ are respectively the minimum and the actual capital ratios under Basel II such that $0<w_{L}<w=1<w_{H}$. The bank determines its loan allocation between the two borrower segments by choosing a proportion $\gamma \in[0,1]$ of low risk loans according to its risk aversion, market interest rates setting, and the risk weights set by the regulator. Therefore $\mathrm{L}_{\mathrm{L}}=\gamma \mathrm{L}$ and $\mathrm{L}_{\mathrm{H}}=(1-\gamma) \mathrm{L}$. Concerning market interest rates, we consider two gross rates of return on the asset side: $\tilde{r}_{H}=\left\{\begin{array}{ll}\bar{r}_{H} & \text { with probability } \quad q \\ \underline{r}_{H}=0 & \text { with probability }(1-q)\end{array}\right.$ and $r_{L}$ respectively for high and low risk loans ${ }^{1}$. We also consider two gross rates of return on the liability side: the cost of equity $\left(r_{K}\right)$ and the cost of insured deposit $\left(r_{D}\right)$ with $1<r_{D}<r_{K}<r_{L}^{2}$. We assume a risk neutral bank with the high risk loan being efficient. Hence, $E\left(\tilde{r}_{H}\right)=q \bar{r}_{H}>r_{L}$.

With all these assumptions, the general expected profit function is written as $^{3}$ :

$E\left(\pi_{G}\right)=r_{L} \gamma L+E\left(\tilde{r}_{H}\right)(1-\gamma) L-r_{D} D-r_{K} K$

\section{BANK PORTFOLIO CHOICE UNDER BASEL II}

Perfect information between the bank and the supervisor

In line with previous studies and in order to only focus on the main interest of this paper, which is loan portfolio allocation, we consider capital requirement as a binding constraint. This assumption allows us to rule out the question of determining the optimal capital ratio. However, as recent studies show, the regulatory capital requirement is far from being binding in reality. For instance, Flannery and Rangan [2008] show that market discipline makes banks usually hold more than the regulatory capital ratio. However, as far as

\footnotetext{
${ }^{1}$ Here the low risk rate of return is assumed certain.

${ }^{2}$ For reasons why equity is more costly than debt, the literature mentions tax rules, agency costs of equity, the relative facility in deposit collection.

${ }^{3}$ Hereafter, we drop the expectation operator $(E())$ at the left hand side of the equation for simplicity and substitute $q \bar{r}_{H}$ for $E\left(\tilde{r}_{H}\right)$ at the right hand side of the equation.
} 
the minimum regulatory capital ratio is used as a benchmark, it remains a relevant constraint ${ }^{4}$. That said, the program maximisation becomes unconstrained:

$\max \pi_{2}=r_{L} \gamma L+q \bar{r}_{H}(1-\gamma) L-r_{D} D-r_{K} K$

Where $K=k\left(w_{L} \gamma+w_{H}(1-\gamma)\right) L$

We determine the portfolio allocation of the bank:

$\frac{\partial \pi_{2}}{\partial \gamma}=\left(r_{L}-q \bar{r}_{H}\right) L+r_{K} k\left(w_{H}-w_{L}\right) L \stackrel{\geq}{<} 0$

The bank decision depends not only on interest rates differentiation, but also on the risk weights differentiation assigned by the regulator. Expression (3) is higher for high risk weight differentiation. Thus, when $\left(w_{H}-w_{L}\right)>\frac{q \bar{r}_{H}-r_{L}}{r_{K} k}$, the optimal choice for the bank will always be low risk assets $(\gamma=1)$, which is a corner solution, in order to benefit from low capital cost.

Result 1: Under the standard framework of Basel II, bank portfolio reshuffling depends, not only on the interest rates charged on low risk and high risk assets ${ }^{5}$, but also on risk weights differentiation. The higher the gap between risk weights for high risk and low risk assets $\left(w_{H}-w_{L}\right)$ is, the more probable the choice of low risk assets $(\gamma=1)$ will be.

This result is in line with the previous literature that conjectures a potential specialization under Basel II. The idea goes as follows: on the one hand, because equity is costly and given that Basel II recognizes risk sensibility and requires low capital for low risk, which is a new feature compare to Basel I and, on the other hand, as Basel II fails to incorporate capital charges for concentration risk, the risk diversification does not appeal beneficial in terms of capital cost saving. All in all, these studies conjecture a kind of "cherrypicking", large and sophisticated banks adopting Basel II would focus on low risk borrowers and benefit from low capital charges and hence offer competitive borrowing conditions to this low risk segment (Repullo and Suarez [2004]). Small and unsophisticated banks which stick with Basel I, as they cannot overcome the high implementing cost of Basel II, would also have a competitive advantage in high risk segment. Whereas high risk borrowers require higher capital charges under Basel II, they still require the same amount of capital under Basel I. Therefore, it is argued that those banks that remain under Basel I could offer lower borrowing cost to this segment and therefore specialize in high risk loans. This specialization is worrisome in the sense that high risk borrowers end up in the portfolios of small banks with less risk management skills (Rime [2005]). However, as argued by Feess and Hege [2008], by confining high risk assets into Too Small To be Bailed Out banking institutions, Basel II has the merit of sheltering the banking system from systemic risk.

So far, we followed the previous literature and considered the standard framework built on the sole minimum capital requirements (Pillar 1) assuming perfect supervision. In the following section, we question this potential specialization by considering a more realistic view that relaxes the perfect supervision assumption.

Asymmetric information between the bank and the supervisor

\footnotetext{
${ }^{4}$ Our conclusions still hold when we relax the binding assumption and consider the capital ratio as a choice variable to be determined.

${ }^{5}$ In a longer version of the paper available at http://congres.afse.fr/docs/2010/499784rugemintwari_nov2009.pdf we study the bank portfolio choice under the risk insensitive capital regulation and we show that it depends solely on rates of returns highlighting the well know result of regulatory arbitrage (Jones [2000]). The robustness check regarding the binding assumption is also available in the same version (see the preceding footnote).
} 
In the previous section, we ignored the possible asymmetric information that could exist between regulators and the bankers. Here we consider that, on the one hand, banks and regulator's incentives are not perfectly aligned and on the other hand, Basel II confers to the banks a certain superiority in terms of information as banks control entirely the information they communicate to the supervisor concerning their risk taking and the corresponding regulatory capital. To motivate our approach, suffice to read the excerpt below from BlundellWignall and Atkinson ([2008], p.78-79) quoting a senior investment banker wishing to remain anonymous: "We started looking at the implications of Basel II from the day it was published back in 2004 ... What you have to understand about complex regulations that affect our business is that we work intensively to minimise the impact they have on our bottom line... The more complex the structure the more scope there is for finding ways around it! It amazes me that regulators asked us to set our capital regulation weights, given the way the incentives are...But good luck to any supervisors who want to find out what is going on inside businesses - that is difficult for insiders to know fully and impossible for outsiders... The supervisors can never match this with the best will in the world."[Emphasis added]

From this excerpt, we infer that asymmetric information could exist at two levels as regards to the computation of the regulatory capital. On the one hand, it is difficult for banks to perfectly gauge the risk they take and hence, there is limited information between the bank and the borrower in this case ${ }^{6}$. On the other hand, Basel II endows the bank with the possibility to fully control what it communicates to the supervisor and hence there is limited information between the bank and the supervisor. Thus, we reasonably consider that the bank knows more than the supervisor does. In this model, we therefore focus on the imperfect information between the bank and the supervisor by assuming that what is impossible for the bank to know is also impossible for the supervisor.

We assume a proportion $i \in[0,1]$ reflecting the bank's incentives to report high risk assets as low risk assets. Of course, there is a cost associated with this misreport when it is discovered by the supervisor. We consider that the bank succeeds to understate its risk with an exogenous probability $p$ and therefore the supervisor discovers the bank's game with probability $(1-p)$ and imposes a certain fine $f$, proportional to the magnitude of the bank's "cheating" 7 .

Actually two regulatory penalties exist (Freixas and Parigi [2008]): increasing required capital and restrictions on the portfolio of risky assets, i.e. the prohibition of investments in certain assets. In this paper, we only consider the former. This choice is backed by the third principle set in the BIS founding document of Basel II (BCBS ${ }^{8}$ [2006], p.211-212). It stipulates that, "supervisors should take appropriate action if they are not satisfied with the results of the bank's own risk assessment and capital allocation. [They] should expect banks to operate above the minimum regulatory capital ratios and should have the ability to require banks to hold capital in excess of the minimum".

We consider that the actual share of low risk assets is still equal to $\gamma$ and its share of high risk assets is $(1-\gamma)$. However, in order to reduce its required capital cost, the bank could decide to report a higher share of low risk asset to benefit from the low risk weight $\left(w_{L}\right)$ associated with it. Therefore, with the probability $p$, the bank reports and the supervisor sees a higher share of low risk assets $\gamma^{\prime}$. Where $\gamma^{\prime}=\gamma+i(1-\gamma)$. As discussed above, with

\footnotetext{
${ }^{6}$ This could particularly be true during the boom period where it is well known that "market-price based, risksensitive models tell banks in the up-cycle that risks have fallen and capital is sufficient for more risk-taking" Goodhart and Persaud [2008].

7 The same reasoning applies if we consider that the bank unwillingly understates its risk taking. For convenience, we will only refer to "cheating".

${ }^{8}$ BCBS stands for the Basel Committee on Banking Supervision.
} 
probability $(1-p)$, the supervisor requires the dishonest bank to hold a higher regulatory capital ratio $k+f k$, where $f=s i(1-\gamma)$ is the fine. We assume that only banks that satisfy the sanctions remain in activity. The proportionality coefficient $s \geq 0$ represents the supervisor's severity. Hence, the new bank profit function under asymmetric information is written as:

$$
\begin{aligned}
\pi_{2}^{A I}= & r_{L} \gamma L+q \bar{r}_{H}(1-\gamma) L-r_{D} D- \\
& r_{K} k L\left[p\left(w_{L} \gamma^{\prime}+w_{H}\left(1-\gamma^{\prime}\right)\right)+(1-p)(1+f)\left(w_{L} \gamma+w_{H}(1-\gamma)\right)\right]
\end{aligned}
$$

With this expression, we are able to assess whether the bank has incentives to understate its risk taking, and if so, under which conditions this bank behaviour is possible. To do so, we compare profit functions under Basel II with perfect supervision (equation(2)) and Basel II with supervision under asymmetric information (equation(4)). For this purpose, we solve the following inequality: $\pi_{2}^{A I}-\pi_{2}>0$ for sanctions magnitude $s$. We get the following result that we call the risk understating condition (RUC):

$\pi_{2}^{A I}-\pi_{2}>0$ for $s<s_{\min }=\frac{p\left(w_{H}-w_{L}\right)}{(1-p)\left(w_{H}-\gamma\left(w_{H}-w_{L}\right)\right.} 9$

Expression (5) means that, for a given value of bank's ability to understate its risk $p$, unless the supervisor's sanction is above a certain minimum $s_{\text {min }}$, the bank will benefit from understating a portion $i \in] 0,1]$ of high risk loans as low risk loans.

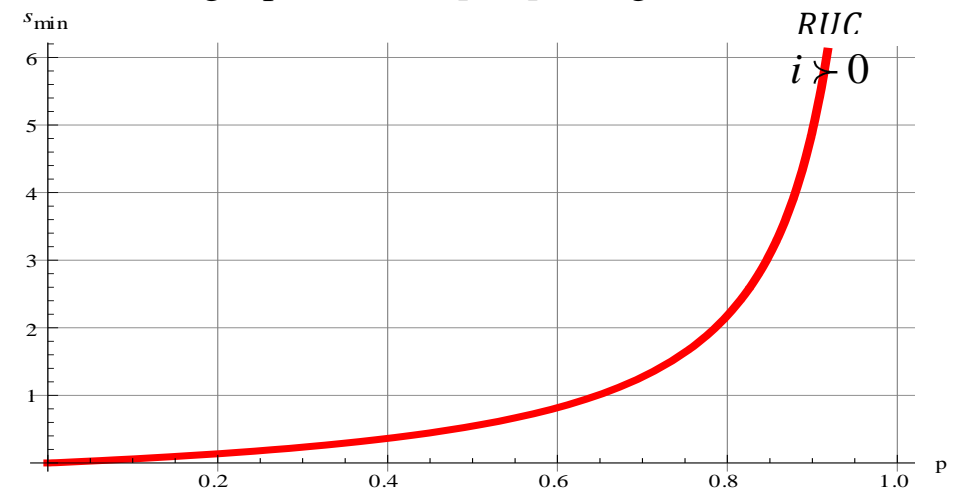

Figure 1: Relationship between the bank's ability to misreport $p$ and the required supervisor's minimum sanction $s_{\text {min }}$ needed to have $i=0^{10}$.

According to the chart above, we can see that for a mere $20 \%(p=0.8)$ chance of the supervisor to detect bank's game, he needs to be tough enough by imposing harsh sanctions mounting to $s=2.18$ at least. This implies, under our assumptions, an extra capital ratio to the regulatory minimum requirement $f k=8.72 \%$ and therefore, the bank should hold a risk weighted capital ratio of $16.72 \%$ at least.

Now that we have determined the conditions under which the bank could misreport its risk taking to maximise its profit, we can determine the optimal choice of the bank as regards to its actual share of low risk assets and its misreporting incentives magnitude. Hence, the maximisation of $\pi_{2}^{A I}$ with respect to $\gamma$ and $i$ gives the following system of two equations:

$$
\left\{\begin{array}{l}
\frac{\partial \pi_{2}^{A I}}{\partial \gamma}=\left(r_{L}-q \bar{r}_{H}\right) L+r_{K} k\left(w_{H}-w_{L}\right) L\left[p(1-i)-(1-p)\left(2 s i \gamma-s i-\frac{w_{H}}{w_{H}-w_{L}} s i-1\right)\right]=0 \\
\frac{\partial \pi_{2}^{A I}}{\partial i}=r_{K} k\left(w_{H}-w_{L}\right) L\left[p-(1-p) s\left(\frac{w_{H}}{w_{H}-w_{L}}-\gamma\right)\right]=0
\end{array}\right.
$$

\footnotetext{
${ }^{9}$ One can show that, when $p=1$, i.e., when the bank has the full ability to cheat, it could reap higher profit by misreporting its risk-taking for every possible sanction $s$.

${ }^{10} \mathrm{We}$ assume (for all figures) that $w_{L}=0.8, w_{H}=1.4$ and $\gamma=0.5$. Other configurations do not modify the main conclusion. For instance, when the risk weight gap is less than the one assumed above, we find that for low probability $p$, the minimum sanction is rather low (the opposite is true), but for high values of $p, s_{\min }$ remains very high.
} 
The second derivative of $\pi_{2}^{A I}$ with respect to $\gamma$ shows that we have a concave function and therefore, the programme maximisation admits a maximum. We derive the optimal actual low risk asset share $\gamma^{*}$ and bank's optimal incentives $i^{*}$ which are given by the expressions:

$\gamma^{*}=\frac{w_{H}}{w_{H}-w_{L}}-\frac{p}{(1-p) s}$ and $i^{*}=\frac{r_{K} k\left(w_{H}-w_{L}\right)-\left(q \bar{r}_{H}-r_{L}\right)}{r_{K} k\left((1-p) s w_{L}-p\left(w_{H}-w_{L}\right)\right)}$

We see that the bank maximises its profit by diversifying its portfolio. Above $\gamma^{*}$, its profit decreases and hence, the bank rationally chooses $\left(1-\gamma^{*}\right)$ of high risk assets. The expression (8) shows that the higher the gap between low and high risk weight asset $\left(w_{H}-w_{L}\right)$, the higher the supervisor's severity $s$ and/or the lower the ability to "cheat" $p$ are, the higher the optimal low risk share $\gamma^{*}$ should be.

Result 2: In presence of asymmetric information between banks and the supervisor, the bank has incentives to understate its risk taking and the optimal portfolio allocation is no more a corner solution. There is an optimal low risk asset share $\gamma^{*}$ above which the bank is not willing to go.

We can infer from the expression (5) that $\lim _{p \rightarrow 1} s_{\min }=\infty$. Therefore it seems difficult, if not impossible, for the supervisor to devise appropriate sanctions to deter the bank from misreporting its risk assessment when the regulator can only detect bank's wrongdoing with very limited ability (high values of $p$ ). Thus, in the following section, we study the suggestion of coupling Basel II with a simple leverage ratio ${ }^{11}$ as envisaged in the recent recommendations known now as Basel III (Caruana [2010]).

\section{BANK PORTFOLIO CHOICE UNDER BASEL II PLUS A LEVERAGE RATIO}

Here, we consider a case in which the regulator requires the bank to hold simultaneously a risk weighted capital ratio (Basel II) and a simple capital leverage ratio. Hence, the bank has to satisfy ${ }^{12}$ :

$$
\left\{\begin{array}{l}
k_{L R}=\frac{K}{L} \geq k \\
k_{2}=\frac{K}{w_{L} \gamma L+w_{H}(1-\gamma) L} \geq k
\end{array}\right.
$$

The bank profit functions are written as:

$$
\pi_{2 L R}=r_{L} \gamma L+q \bar{r}_{H}(1-\gamma) L-r_{D} D-r_{K} k L \max \left\{1,\left(w_{L} \gamma+w_{H}(1-\gamma)\right)\right\}
$$

under perfect supervision or,

$$
\begin{aligned}
\pi_{2 L R}^{A I}= & r_{L} \gamma L+q \bar{r}_{H}(1-\gamma) L-r_{D} D- \\
& r_{K} k L \max \left\{1,\left[p\left(w_{L} \gamma^{\prime}+w_{H}\left(1-\gamma^{\prime}\right)\right)+(1-p)(1+f)\left(w_{L} \gamma+w_{H}(1-\gamma)\right)\right]\right\}
\end{aligned}
$$

under imperfect supervision.

In order to investigate the bank behaviour concerning its incentives to misreport its own risk assessment, we proceed like previously by solving $(11)-(10)>0$. This inequality

\footnotetext{
${ }^{11}$ To our knowledge, only Blum [2008] has modelled the suggestion of coupling Basel II with a simple leverage ratio. However our approach differs from his on several aspects. For instance, we define low and high risk banks subsequent to the bank portfolio choice while Blum's interpretation of the two types is that the safe banks are operated by competent, efficient managers and the risky banks are operated by less competent managers who do not have access to the safe, profitable projects. He ignores the question of portfolio choice which is at the core of our paper.

${ }^{12} \mathrm{We}$ assume the same minimum regulatory capital ratio $k$ for simplicity. In the future research, it could be interesting to conduct calibrations on what should be the appropriate value of $k$ for the leverage ratio.
} 
offers technically four potential cases where only two are consistent with our framework. In fact, if the risk adjusted capital is less than the leverage capital, therefore the bank has to satisfy the latter and there is no risk understating ${ }^{13}$. Thus, we only consider that the risk adjusted capital under Basel II with perfect information is equal or higher than the leverage capital. Hence, the two possible cases detailed below correspond to the situation where both the risk adjusted capital under perfect and imperfect information are above the simple leverage capital and the situation where the risk adjusted capital under imperfect information is less than the simple leverage capital. Note however that in the latter case, the bank will be obliged to hold the minimum capital required by the leverage capital constraint.

The leverage capital ratio constraint is not binding

In this case, the situation is such that the risk adjusted capital, both under perfect and imperfect supervision, is superior to the simple leverage ratio. To find out under which conditions the bank could benefit from understating its risk taking, we solve the following system compounded by three inequalities to be simultaneously satisfied. That is:

$$
\left\{\begin{array}{l}
\pi_{2 L R}^{A I}-\pi_{2 L R}>0 \\
\left(w_{L} \gamma+w_{H}(1-\gamma)\right)-1 \geq 0 \\
p\left(w_{L} \gamma^{\prime}+w_{H}\left(1-\gamma^{\prime}\right)\right)+(1-p)(1+f)\left(w_{L} \gamma+w_{H}(1-\gamma)\right)-1 \geq 0
\end{array}\right.
$$

The system is satisfied, i.e. the bank makes profit by understating its risk $\left(\pi_{2 L R}^{A I}-\pi_{2 L R}>0\right)$ given that the leverage ratio is not binding under the following conditions:

Table 1: Risk understating conditions in the case of non binding leverage capital constraint

\begin{tabular}{|c|c|c|c|}
\hline \multicolumn{3}{|c|}{$\pi_{2 L R}^{A I}-\pi_{2 L R}>0$} \\
\hline Low "cheating" ability & \multicolumn{3}{|c|}{ High "cheating" ability } \\
\hline $0<p \leq p_{\min }$ & \multicolumn{2}{|c|}{$p_{\min }<p<1$} & $p=1$ \\
\hline $0<s \leq s_{\min }$ & $0 \leq s<s_{\min }^{\prime}$ & $s_{\min }^{\prime} \leq s<s_{\min }$ & $\forall s \geq 0$ \\
\hline$\forall 0<i \leq 1$ & $0<i \leq i_{\max }$ & $\forall 0<i \leq 1$ & $0<i \leq 1-\frac{1-w_{L}}{\left(w_{H}-w_{L}\right)(1-\gamma)}$ \\
\hline
\end{tabular}

Where: $p_{\min }=\frac{\left(w_{H}-1\right)\left(w_{H}-w_{L}\right)}{(1-\gamma)\left(w_{H}-w_{L}\right)}, s_{\min }=\frac{p\left(w_{H}-w_{L}\right)}{(1-p)\left(w_{H}-\gamma\left(w_{H}-w_{L}\right)\right)}$,

$s_{\text {min }}^{\prime}=\frac{1+(1-p)(1-\gamma) w_{H}-w_{L}(p+\gamma(1-p))}{(1-p)\left(w_{H}-\gamma\left(w_{H}-w_{L}\right)\right)}$ and $i_{\text {max }}=\frac{1-(1-\gamma) w_{H}-\gamma w_{L}}{(1-\gamma)\left(\left(w_{H}(s(1-p)(1-s \gamma)-p)-w_{L}(p+s(1-p)) \gamma\right)\right.}$

These results have to be compared with those obtained under sole Basel II in order to highlight the role, if any, of supplementing the simple leverage to Basel II. We notice that the results in the first column are equivalent to those under sole Basel II. Thus, we infer from this similarity that under low bank's ability to understate its risk taking (low $p$ ) (or equivalently high supervisor's power), the simple leverage ratio is superfluous and thus, unnecessary in curbing bank's incentives to misreport its risk taking. On contrary, when $p$ is high (remaining columns), the fraction of high risk assets that the bank could potentially masquerade as low risk assets is bounded from above and depend on $p$ and $s$. One can easily show that the upper bound limit of $i$ decreases as $p$ gets higher and higher. It reaches the minimum when $p=1$ (see figure 3 below).

\footnotetext{
${ }^{13}$ Formally, we have(11) $\Leftrightarrow(10)$.
} 


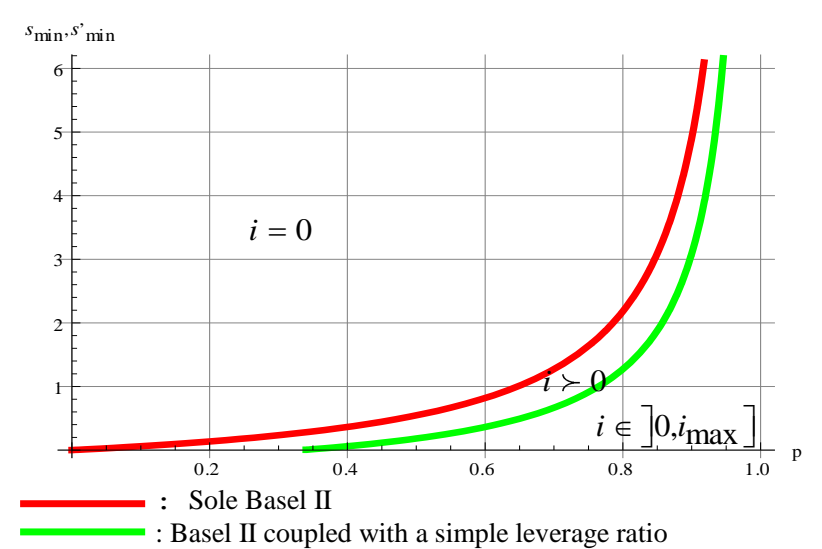

Figure 2: Relationship between the bank's ability to misreport $\boldsymbol{p}$ and the supervisor's minimum sanctions $\boldsymbol{s}_{\min }$ and $\boldsymbol{s}_{\min }^{\prime}$.

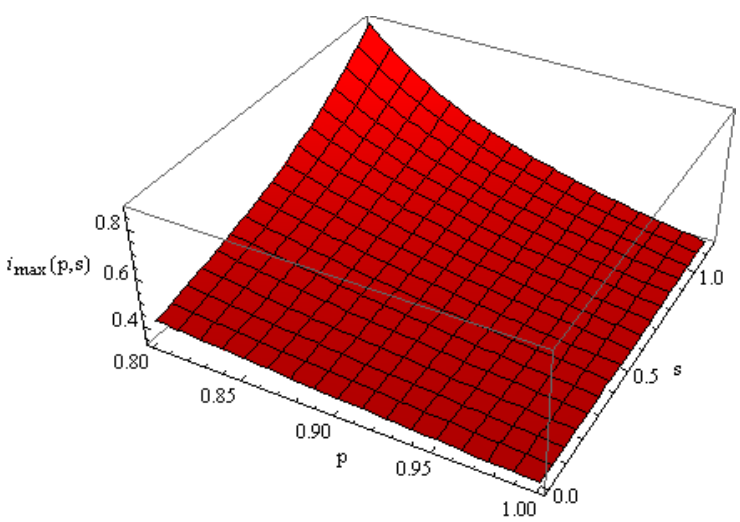

Figure 3: Relationship between the actual supervisor's sanction $\boldsymbol{s}$, the bank's ability $\boldsymbol{p}$ and incentives $\boldsymbol{i}_{\text {max }}$ to misreport its risk.

From figure 2 we can see that, even though the minimum supervisor's sanction needed to deter completely the bank from misreporting its risk remains the same, that is $i=0$ for every $s>s_{\min }$, we notice that the simple leverage ratio introduces an upper bound limit $i_{\max }$ for lower supervisor's minimum sanction than $s_{\min }^{\prime}$ as detailed on figure 3 .

Figure 3 shows how supplementing Basel II with the simple risk insensitive leverage ratio affects the bank's incentives to understate their risk reporting. It depicts for a given value of bank's ability to misreport its risk $p>p_{\text {min }}$, the range of supervisor's minimum sanction $s$ and the corresponding upper bound limit of bank's incentives to misreport its risk $i_{\text {max }}$. The figure highlights the role of the simple leverage ratio in curbing bank's incentives to "cheat". This means that, for a given supervisor's sanction $s$ lower than $s_{\text {min }}^{\prime}$, the bank would not misreport a fraction of high risk asset as low risk asset higher than $i_{\max }$ without breaching the simple leverage ratio requirement. For instance, for bank's ability to cheat $p=0.8$, the supervisor can completely deter the bank from cheating by setting a sanction $s \geq s_{\text {min }}=$ 2.18. If not, the chart shows that for lower sanction than $s_{\min }^{\prime}=1.27$, the maximum fraction of high risk asset the bank could misreport is lower than the unity $(i=1)$ found under sole Basel II. For example, for the same $p=0.8$, if $s=1$, the maximum fraction the bank could misreport is $i_{\text {max }}=0.77$ and the upper bound limit decreases for lower sanction $s$ or higher bank's ability $p$. We have $i_{\max }=0.42$ for $s=0$ for instance. This limiting role of the leverage ratio is of great importance notably if we consider the issue of supervisor's forbearance.

The leverage capital ratio constraint is binding

In this case, we consider the situation where the bank understates significantly its risk reporting and therefore the risk adjusted capital under Basel II with imperfect information is lower than the leverage capital. Hence, the former system of three inequalities is slightly modified and becomes:

$$
\left\{\begin{array}{l}
\pi_{2 L R}^{A I}-\pi_{2 L R}>0 \\
\left(w_{L} \gamma+w_{H}(1-\gamma)\right)-1 \geq 0 \\
p\left(w_{L} \gamma^{\prime}+w_{H}\left(1-\gamma^{\prime}\right)\right)+(1-p)(1+f)\left(w_{L} \gamma+w_{H}(1-\gamma)\right)-1<0
\end{array}\right.
$$

Thus, when the leverage ratio binds, the bank makes profit by understating its risk only under these conditions: 
Table 2: Risk understating conditions in the case of binding leverage capital constraint ${ }^{14}$

\begin{tabular}{|l|l|}
\hline \multicolumn{2}{|c|}{$\pi_{2 L R}^{A I}-\pi_{2 L R}>0$} \\
\hline \multicolumn{2}{|c|}{ High "cheating" ability } \\
\hline$p_{\text {min }}<p<1$ & $p=1$ \\
\hline $0 \leq s<s_{\text {min }}^{\prime}$ & $\forall s \geq 0$ \\
\hline$i_{\text {min }}^{\prime}<i \leq 1$ & $1-\frac{1-w_{L}}{\left(w_{H}-w_{L}\right)(1-\gamma)}<i \leq 1$ \\
\end{tabular}

Notice that, contrary to the previous non binding case, the situations where the bank can make profit by understating its risk are rather rare. For instance, the case where the bank has less capability $\left(p \leq p_{\min }\right)$ no longer exists. The table above indicates that the bank only benefits from understating its risk if, at the same time, it is capable enough, the supervisor is less severe and it masquerades a considerable fraction of high risk as low risk assets. In this case too, we can see how the coexistence of the simple leverage ratio and Basel II is superior to the sole Basel II. Whereas the bank could gain by "cheating" for every value of $p$ and $i$ when $s<s_{\min }$ under sole Basel II, now, not only $p$ has to be superior to $p_{\min }$ and $i>i_{\text {min }}^{\prime}$, but also the supervisor's minimum sanction necessary to deter the bank from "cheating" $s_{\min }^{\prime}$ is lower $\left(s_{\min }^{\prime}<s_{\min }\right)$.

All in all, coupling Basel II with a simple leverage ratio has several merits when the supervisor ability to detect and sanction banks' wrongdoing is weak. We can see how the simple leverage ratio, on the one hand, substantially lowers the maximum the bank can misreport when the supervisor is completely unable to detect and/or sanction the bank (non binding case). In the other hand, it tightens the conditions under which the bank could "cheat" (binding case). The supplement of the simple leverage requirement prevents banks from holding a capital ratio lower than $k=K / L$ which could otherwise be possible under some circumstances of the sole Basel II. Indeed, even in a situation where the bank has full ability to "cheat" $(p=1)$ and the sanction is absent $(s=0)$, the leverage ratio guarantees that the bank holds at least a capital level $k L>k w_{L} L$.

Result 3: When supervisor's ability to detect bank's risk misreporting and its sanction enforcement are relatively weak, the supplement of a simple leverage ratio to self risk reporting Basel II helps to curb bank's incentives to understate its risk.

\section{CONCLUSION}

We present a simple model that shows the promises and the limits of Basel II and we argue that the supplement of a simple leverage to Basel II offers a higher outcome.

Basel II was built on the idea nicely put by Prescott [2004]: "After all, who knows the risks of bank's assets better than the bank itself". Therefore, it seems reasonable to consider that the bank's supervisor has only limited ability to know the true risk faced by the bank. Moreover, given the high cost of capital and the bank tendency to save on regulatory capital, high risk banks have less, if at all, incentives to reveal their true type. That is the reason why it is important to go beyond the first Pillar and assess how supervisors can induce truthful

\footnotetext{
${ }^{14} p_{\min }, s_{\min }^{\prime}$ are the same as in Table 1 and $i_{\min }^{\prime}$ has the same expression as $i_{\text {max }}$ in Table 1.
} 
bank reports on their risk taking. It is what this paper has tried to do. We show that sanctions or penalties imposed for non-compliance are critical for determining bank incentives. However, in some circumstances, that is when supervisors' ability to detect bank's misdeed is very low, sanctions needed under sole Basel II to affect the incentives of banks to send accurate reports are so huge that it seems impossible to implement. In this case, we show that coupling Basel II with a simple leverage ratio is necessary as it lowers the minimum sanction needed to induce truthful risk report and curbs bank's incentives to "cheat". This conclusion is consistent with the very few formal studies that analyse this issue (Blum [2008]) and the various propositions subsequent to the recent subprime mortgage crisis (Hildebrand [2008], BCBS [2009] for instance) that advocate a leverage ratio as a backstop to Basel II. The simple leverage ratio which is easily computable and verifiable reveals itself as a necessary tool to curb banks' incentives to understate the risks they take. It also appears as a necessary palliative remedy to supervisor's imperfection and forbearance.

\section{REFERENCES}

BCBS [2006], "International convergence of capital measurement and capital standards: A revised framework - comprehensive version", June.

BCBS [2009], "Basel II capital framework enhancements announced by the Basel Committee", July 13.

BLUM J. [2008], "Why 'Basel II' may need a leverage ratio restriction", Journal of Banking \& Finance, 32 (8), p.1699-1707.

Blundell-Wignall A., AtKinson P. [2008], "The Sub-prime Crisis: Causal Distortions and Regulatory Reform", in (ed.), Bloxham P., Kent C., Lessons from the Financial Turmoil of 2007 and 2008, Sydney, Reserve Bank of Australia, p.55-102.

CARUanA J. [2010], "Basel III: towards a safer financial system”, Speech at the $3^{\text {rd }}$ Santander International Banking Conference, Madrid, Sept. 15.

FEess E., HEGE U. [2008], "The Basel II and the Value of Bank differentiation”, CFS Working Paper $\mathrm{n}^{\circ} 2004 / 25$.

FLANNERY M., RANGAN K. [2008], "What Caused the Bank Capital Build-up of the 1990s?", Review of Finance 12 (2), p.391-429.

FREIXAS X., PARIGI B. [2008], "Banking regulation and prompt corrective action" CESifo Working Paper $\mathrm{n}^{\circ} 2136$.

FurFINE G. [2001], "Bank Portfolio Allocation: The Impact of Capital requirements, regulatory Monitoring, and Economic Conditions", Journal of Financial Services Research 20 (1), p.33-56.

Goodhart C., Persaud A. [2008], "How to avoid the next crash", Financial Times, Jan. 30. HILDEBRAND P., [2008], "Is Basel II Enough? The benefits of a Leverage Ratio", Financial Markets Group Lecture. LSE, Dec. 15.

JONES D. [2000], "Emerging problems with the Basle Accord: Regulatory capital arbitrage and related issues", Journal of Banking \& Finance 24 (1-2), p.35-58.

PRESCOTT E. [2004], "Auditing and bank capital regulation," Federal Reserve Bank of Richmond Economic Quarterly 90 (Fall), p.47-63.

RePullo R., SuAReZ J. [2004], “Loan Pricing under Basel Capital Requirements," Journal of Financial Intermediation, 13 (4), p.496-521.

RIME B. [2005], "Will Basel II Lead to a Specialization of Unsophisticated Banks on HighRisk Borrowers?", International Finance 8 (1), p. 29-55. 